\title{
ESR age of Pleistocene shells measured by radiation assessment
}

\author{
Motoli IKeYA ${ }^{1}$ and Kazuo OHMURA ${ }^{2}$ \\ Technical College, Yamaguchi University, Ube, Yamaguchi $755,{ }^{1}$ and \\ Dia Consultant Co. Ltd., 3-1631, Ikebukuro, Tokyo $171,{ }^{2}$ Japan
}

(Received August 9, 1983: Accepted October 13, 1983)

\begin{abstract}
Absolute electron spin resonance (ESR) ages of Pleistocene shells from Hiradoko and Uji shell beds in Noto Peninsula, Central Japan were deduced from the total absorbed dose of natural radiation (TD) and the internal and external radiation dose. The internal dose from inside the shell was assessed using the ${ }^{238} \mathrm{U},{ }^{232} \mathrm{Th}$ and $\mathrm{K}$ contents and newly developed theoretical equation of TD based on uranium-series disequilibrium in a finite medium. The external environmental radiation was measured by thermoluminescent dosimeter (TLD) of $\mathrm{CaSO}_{4}(\mathrm{Tm})$. The ESR ages of around 120,000 years for shells from both shell beds agreed fairly well with coral ages in the same shell beds determined with ${ }^{230} \mathrm{Th} /{ }^{234} \mathrm{U}$ dating (OMURA, 1980).
\end{abstract}

\section{INTRODUCTION}

A microwave spectroscopy of electron spin resonance (ESR) has been successfully used to date carbonates like stalactites and stalagmites (IKEYA 1975), bones (IKEYA 1978, IKEYA and MIKI 1980), and shells and corals (IKEYA and OHmura 1981, 1983). The total dose of natural radiation (TD) given to the material since its formation has been determined from the ESR signal intensity of defects produced by natural radiation by employing the method of additive artificial irradiation similar to that used in thermoluminescence (TL) dating (AITKEN, 1974; ZELLER et al. 1967).

Cross check of TD obtained by ESR with that by TL was made for a stalctite from the Akiyoshi cave (MIKI and IKEYA 1978). This was also the first $\mathrm{Tl}$ dating of a stalactite in stratigraphic growth order. The TD's of fossil shells were compared with geological and radioisotope dating ages (IKeYA and OHmura 1981). The annual dose rate was tuned in these works to explain the obtained TD and informed ages. In this respect, ESR dating of shells was only a relative dating at that stage. More recently, absolute ESR ages were calculated for corals from marine terraces in Ryukyu Islands assum- ing an infinite medium of coral reef and uranium-series radiation disequilibrium and compared with ${ }^{14} \mathrm{C}$ - and ${ }^{230} \mathrm{Th} /{ }^{234} \mathrm{U}$ ages (IKEYA and OHMura, 1983; IKEYa 1984). Contrary to a massive coral reefs, shells in natural shell beds can not be regarded as an infinite medium for the assessment of natural radiation.

In this paper, we report the procedures to assess the radiation dose for a finite size shell and present the ESR ages of shells determined from the obtained TD, the ${ }^{238} \mathrm{U}$ content and the external radiation. Shells from Hiradoko and Uji shell beds, Noto Peninsula, Central Japan are used since information is available on the ${ }^{238} \mathrm{U}$ content and ${ }^{230} \mathrm{Th} /{ }^{238} \mathrm{U}$ ages. Results indicate that shells with small amount of ${ }^{238} \mathrm{U}$ are mainly damaged by the external radiation.

\section{EXPERIMENTAL}

Late Pleistocene fossil shells were collected from natural shell beds in Hiradoko Terrace, $147^{\circ} 18^{\prime} 16^{\prime \prime} \mathrm{E}, 37^{\circ} 27^{\prime} 04^{\prime \prime} \mathrm{N}, 30 \mathrm{~m}$ above sea level at a quarry about $750 \mathrm{~m}$ south of Hiradoko, Suzu City, Noto Peninsula, Central Japan. The Hiradoko Terrace is correlative with the Shimoseyoshi Terrace in the southern Kanto area. Shells in Uji Terrace, $137^{\circ} 30^{\prime} 51^{\prime \prime}$ E longitude, 
$37^{\circ} 27^{\prime} 51^{\prime \prime} \mathrm{N}, 13$ to $15 \mathrm{~m}$ above sea level were collected from an outcrop about $100 \mathrm{~m}$ west of Honryuji Temple, also in Noto Peninsula as is shown in the locality map in Fig. 1 after A. OMura (1980). Hiradoko and Uji shell beds are considered Holocene or late Pleistocene (UnIE, 1975, Funi, 1976). The ${ }^{14} \mathrm{C}$-age gave 21,200 years and larger than 30,000 years presumably beyond the detection limit of ${ }^{14} \mathrm{C}$ method due to modern carbon contamination. The ${ }^{230} \mathrm{Th} /{ }^{234} \mathrm{U}$ dating of corals (OMURA, 1976, 1980) gave about 120,000 years old ages. Present shell samples have been kindly supplied by A. Omura to investigate the possibility of ESR method as an absolute dating technique for shells. Details on the geological description on both shell beds are given in OMURA (1980).

ESR measurements were made at room temperature with a standard spectrometer using $100 \mathrm{kHz}$ field modulation of $0.1 \mathrm{mT}$. The ${ }^{238} \mathrm{U}$ and ${ }^{232} \mathrm{Th}$ content of some shells was measured by alpha-counting method. The internal total dose of natural radiation by alpha and beta rays were calculated using the concentrations of radioactive elements and a theoretical equation developed in the next section. We evaluated the external total dose by measuring the present dose rate with a commercial thermoluminescent dosimeter (TLD) of $\mathrm{CaCO}_{4}(\mathrm{Tm})$ (National UD$110 \mathrm{~S}$ ), assuming it to be constant since the formation of shells.

\section{Theoretical TD for a Finite Medium}

The total dose of natural radiation (TD) that the shell has received since its formation or crystallization is obtained by exposing the specimen with its initial ESR intensity, $I_{o}$, to the radiation dose of $\mathrm{Q}$ Gy (gray: $1 \mathrm{~Gy}=1 \mathrm{~J} / \mathrm{kg}=$ $100 \mathrm{rad}$ ) from the relation

$$
\mathrm{I}(\mathrm{Q}) / \mathrm{I}_{\mathrm{o}}=(\mathrm{TD}+\mathrm{Q})
$$

or

$$
\mathrm{I}(\mathrm{Q})=\mathrm{I}_{\mathrm{o}}(1+\mathrm{Q} / \mathrm{TD})
$$

where $I(Q)$ is the intensity after addition of $Q$

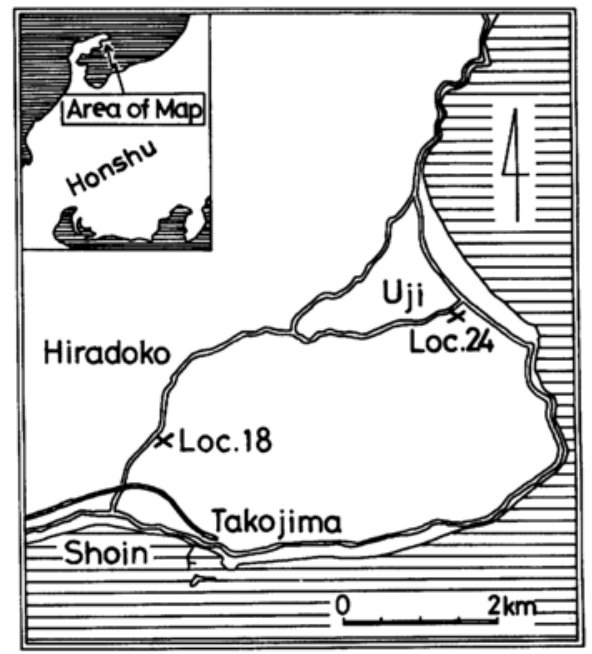

Fig. 1. Locality map of Hiradoko and Uji shell beds in Noto Peninsula, Central Japan following the work by A. OMURA (1980).

Gy. The assessment of natural radiation dose rate, $\mathrm{D}$, on the assumption of radiation equilibrium (BELL, 1979) gives the age, $T_{e}$, simply according to

$$
\mathrm{T}_{\mathrm{e}}=\mathrm{TD} / \mathrm{D}
$$

However, ${ }^{238} \mathrm{U}$-series is in disequilibrium for about 300,000 years (about $4-5$ half lives of ${ }_{\sim}^{234} \mathrm{U}$ ) after the incorporation of ${ }^{238} \mathrm{U}$ as pointed out in TL dating of Quaternary carbonate (WINTLE, 1978). The half lives of ${ }^{234} \mathrm{U}$ and ${ }^{230} \mathrm{Th}$ are $7.5 \times 10^{4}$ and $2.5 \times 10^{5} \mathrm{y}$, respectively. Hence, we must consider time-dependent annual dose rate, $\mathrm{D}(\mathrm{t})$, and integrate it to obtain TD as was made in coral dating (IKEYA and OHMURA, 1983).

The dose rate $D(t)$ was expressed using ${ }^{234} \mathrm{U} /{ }^{238} \mathrm{U}$ and ${ }^{230} \mathrm{Th} /{ }^{234} \mathrm{U}$ activity ratio, $\mathrm{p}$ and $\mathrm{q}$, respectively as

$$
\begin{aligned}
\mathrm{D}(\mathrm{t}) & =\mathrm{D}_{38}+(\mathrm{p}-1) \mathrm{D}_{34}+\mathrm{D}_{30} \mathrm{pq} \\
& =\mathrm{D}+(\mathrm{p}-1) \mathrm{D}_{34}+\mathrm{D}_{30}(\mathrm{pq}-1)
\end{aligned}
$$

where $D_{38}, D_{34}$ and $D$ are the dose rates of ${ }^{238} U$ series disintegrations from ${ }^{238} \mathrm{U}$ to ${ }^{234} \mathrm{U}$, from ${ }^{234} \mathrm{U}$ to ${ }^{230} \mathrm{Th}$ and from ${ }^{230} \mathrm{Th}$ to ${ }^{206} \mathrm{~Pb}$. Numer- 
Table 1. Annual dose rate for radiation equilibrium and parameters of a time dependent dose rate for ${ }^{238} U$ series radiation disequilibrium. Values in parentheses is for $100 \%$ radon or thoron loss

\begin{tabular}{cllllll}
\hline & & & \multicolumn{2}{c}{$\mathrm{D}_{a}$} & \multicolumn{1}{c}{$\mathrm{D}_{\beta}$} & \multicolumn{1}{c}{$\mathrm{D}$} \\
\hline${ }^{238} \mathrm{U}$ & $(\mathrm{ppm})$ & $\mathrm{D}_{\mathrm{U}}$ & 2.783 & $(1.252)$ & $0.1462(0.0609)$ & $0.1148(0.0056)$ \\
${ }^{232} \mathrm{Th}$ & $(\mathrm{ppm})$ & $\mathrm{D}_{\mathrm{Th}}$ & 0.738 & $(0.309)$ & $0.0286(0.0103)$ & $0.0514(0.0208)$ \\
$\mathrm{K}_{2} \mathrm{O}(\%)$ & $\mathrm{D}_{\mathrm{K}}$ & \multicolumn{2}{c}{-} & 0.6893 & 0.2069 \\
${ }^{* * 234} \mathrm{U}-{ }^{230} \mathrm{Th}$ & $\mathrm{D}_{34}$ & 0.2962 & 0. & 0.003 \\
$* *{ }^{230} \mathrm{Th}-{ }^{206} \mathrm{~Pb}$ & $\mathrm{D}_{30}$ & $2.109(0.588)$ & $0.0853(0)$ & $0.1097(0.005)$ \\
\hline
\end{tabular}

* $D_{U}, D_{T h}$ and $D_{K}$ are dose rate $(m G y / y)$ for radiation equilibrium according to BELL (1979). The SI unit $\mathrm{mGy} / \mathrm{y}=1 \mathrm{~mJ} / \mathrm{kg} \cdot \mathrm{y}=100 \mathrm{mrad} / \mathrm{y}$.

** $D_{34}$ and $D_{30}$ are the dose rate for the respective decay in ${ }^{238} U$-series disintegration in equilibrium with 1 ppm of ${ }^{238} U$. The time dependent annual dose rate, $D(t)$, and total dose, $T D(t)$, are shown in Equations (3) and (6).

ical values are listed in Table 1 for alpha, beta and gamma rays together with the ones for equilibrium for $1 \mathrm{ppm}$ of ${ }^{238} \mathrm{U}$ given by BELL (1979). The activity ratios $\mathrm{p}\left({ }^{234} \mathrm{U} /{ }^{238} \mathrm{U}\right)$ and $\mathrm{pq}\left({ }^{230} \mathrm{Th} /\right.$ ${ }^{238} \mathrm{U}$ ) are

$$
\begin{aligned}
\mathrm{p}=1+ & \left(\mathrm{p}_{\mathrm{o}}-1\right) \mathrm{e}^{-\lambda_{34} \mathrm{t}} \\
\mathrm{pq}=1-\mathrm{e}^{-\lambda_{30} \mathrm{t}} & \\
& +\left(\mathrm{p}_{\mathrm{o}}-1\right) \frac{\lambda_{30}}{\lambda_{30}-\lambda_{34}}\left(\mathrm{e}^{-\lambda_{34} \mathrm{t}}\right. \\
& \left.-\mathrm{e}^{-\lambda_{30} \mathrm{t}}\right)
\end{aligned}
$$

where $\lambda_{30}$ and $\lambda_{34}$ are the decay constants of ${ }^{230} \mathrm{Th}$ and ${ }^{234} \mathrm{U}$, respectively. TD can be obtained by integrating Equation (2) from $t=0$ to $\mathrm{t}=\mathrm{T}$ for $1 \mathrm{ppm}$ of ${ }^{238} \mathrm{U}$ as

$$
\begin{aligned}
\mathrm{TD}(\mathrm{T})= & \mathrm{DT}+\mathrm{D}_{34}\left(\mathrm{p}_{\mathrm{o}}-1\right)\left(1-\mathrm{e}^{-\lambda_{34} \mathrm{~T}}\right) \\
& / \lambda_{34}-\mathrm{D}_{30}\left[\left(1-\mathrm{e}^{-\lambda_{30} \mathrm{~T}}\right) / \lambda_{30}\right. \\
& -\left(\mathrm{p}_{\mathrm{o}}-1\right) \frac{1}{\lambda_{34}}(1 \\
& \left.\left.-\frac{\lambda_{33} \mathrm{e}^{-\lambda_{34} \mathrm{~T}}-\lambda_{34} \mathrm{e}^{-\lambda_{30} \mathrm{~T}}}{\lambda_{30}-\lambda_{34}}\right)\right]
\end{aligned}
$$

where the first term results from the radiation equilibrium, the second term is the contribution of extra ${ }^{234} \mathrm{U}$ and the third term is the correction for the insufficient build-up of ${ }^{230} \mathrm{Th}$.

We have considered an infinite medium model for corals in a massive coral reef and calculated th TD versus $\mathrm{T}$ relation on the basis of the concentrations of ${ }^{238} \mathrm{U},{ }^{232} \mathrm{Th}$ and $\mathrm{K}_{2} \mathrm{O}$ (IKeYA and OHMURA, 1983). In the case of shells, the medium is no longer infinite. The alpha and beta rays out of radioactive elements in the finite size shell fully contribute to the TD, while the internal gamma rays with a long range are mostly absorbed by the environmental sediments. Similarly, alpha and beta rays out of the sediments cause radiation damage only at the surface of the shell which is removed by etching chemically or mechanically. Hence, only the gamma rays out of the sediments are taken into consideration as a first step of the radiation assessment.

Internal and external TD must be onsidered to be

$$
\begin{aligned}
\mathrm{TD} & =\mathrm{TD}_{\mathrm{in}}+\mathrm{TD}_{\mathrm{ex}} \\
& =\left(\mathrm{k} \mathrm{TD}_{\alpha},+\mathrm{TD}_{\beta}\right)+\mathrm{D}_{\mathrm{ex}} \mathrm{T}
\end{aligned}
$$

where, $\mathrm{TD}_{\mathrm{in}}$ and $\mathrm{TD}_{\mathrm{ex}}$ are for internal and external TD. The former was calculated using Equation (6). $\mathrm{k}$ is the defect production efficiency by alpha particle and was taken as 0.2 for carbonate. External dose rate $D_{e x}$ for gamma-rays was obtained by embedding the thermoluminescence dosimeter (TLD) of $\mathrm{CaSO}_{4}$ in shell sediments. The age, $T_{d}$, on the assumption of ${ }^{238} \mathrm{U}$-series disequilibrium can be obtained graphically or by iteration using a computer. 


\section{RESULTS}

Figure 2(a) shows an ESR spectrum of a shell from the Uji shell bed. It consists of four types of signals each with a different spectroscopic splitting factor called g-value. They were designated as A, B, C and D from the low field: A $(g=2.996), B(g=2.0037), C\left(g_{\perp}=2.0008\right)$ and $\mathrm{D}\left(\mathrm{g}_{\|}=1.995\right)$. The latter two signals $\mathrm{C}$ and $\mathrm{D}$ are associated with $\mathrm{g}_{1}$ perpendicular to, and $\mathrm{g}_{\|}$, parallel to the c-axis for $\mathrm{CO}_{3}{ }^{3-}$-impurity complex in $\mathrm{CaCO}_{3}$. Previous work on shell dating with ESR indicated that the intensities of signals $\mathrm{C}$ and $\mathrm{D}$ are related with the relative age (IKEYA and OHMURA, 1981).

Figure 2(b) shows the growth of the signal by artificial irradiation. The extrapolation of the linear growth to zero ordinate gives TD of about $110 \mathrm{~Gy}$ following Equation (1'). To avoid the errors due to the overlap of signals, the half of the magnitude of the derivative line for $\mathrm{C}$ signal is taken as a scale indicative of the defect concentration. It should be noted that signals $\mathrm{A}$ and $\mathrm{B}$ do not necessarily give appropriate TDs' proportional to the age. Signal D essentially the same as signal $\mathrm{C}$ is broad and is not used for the determination of TDs. Signal E has weak intensity; and so it is discarded though artificial

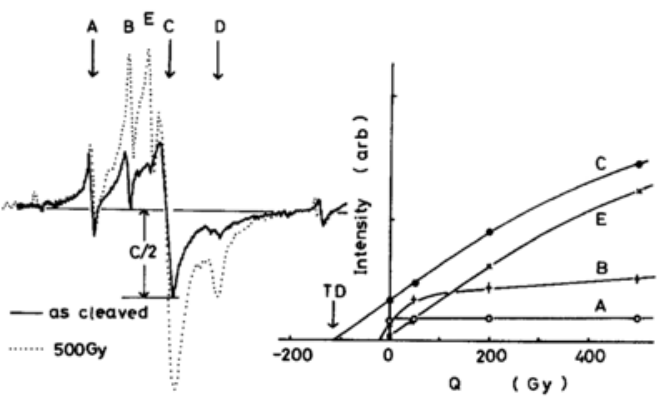

Fig. 2(a). ESR derivative absorption spectrum of Uji shell before and after the artificial additive gamma ray irradiation. The signal positions were indicated by $A, B$, $C$, $D$, and $E$.

(b). Enhancement of the signal magnitude by the artificial irradiation. The extrapolation of the initial part for the signal $C$ gives TD. irradiation enhances it.

Figure 3 shows a typical relation of TD versus $\mathrm{T}$ for a shell from the Hiradoko shell bed. The calculated $\mathrm{TD}, \mathrm{TD}_{\mathrm{in}}$ and $\mathrm{D}_{\mathrm{ex}} \mathrm{T}$ are also indicated in the figure together with those for the case of radiation equilibrium using the kvalue of 0.2. As an example, the TD obtained experimentally is also indicated to obtain the ages for equilibrium $\left(\mathrm{T}_{\mathrm{e}}\right)$ and for disequilibrium $\left(\mathrm{T}_{\mathrm{d}}\right)$.

Table 2 shows the name of shell species, ${ }^{238} \mathrm{U}$ and ${ }^{232} \mathrm{Th}$ contents and the external radiation dose rate determined by TLD and TD with ESR for shells from Uji and Hiradoko shell beds. The ages $T_{e}$ and $T_{d}$ determined from the TD using Equation (6) are compared with the ${ }^{230} \mathrm{Th} /{ }^{234} \mathrm{U}$ ages for corals measured by OMura. The external dose $\left(D_{\mathrm{ex}}\right)$ at Uji shell beds was simply assumed to be the same as at Hiradoko shell beds, since the outcrop had been destroyed. The ESR ages $\left(T_{e}\right)$ for uranium series equilibrium using Bell's equation is generally younger than $T_{d}$ and the reported ages of corals in the shell beds (OMURA, 1980).

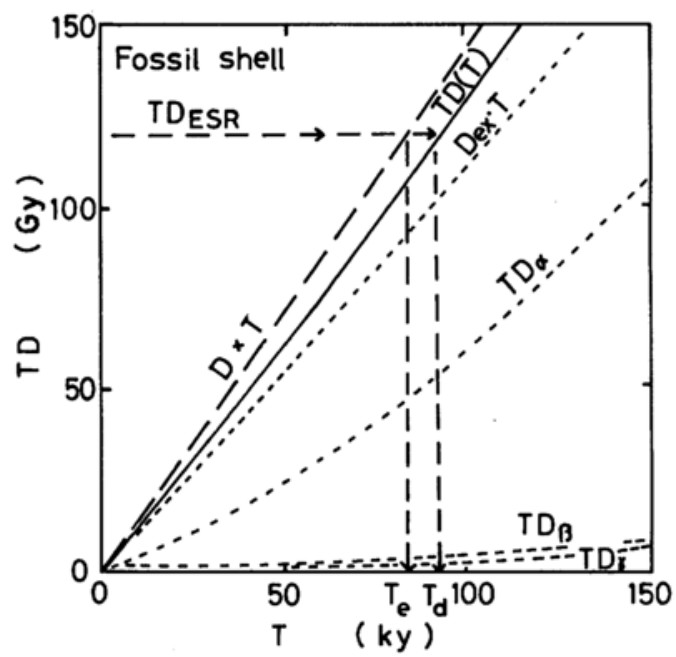

Fig. 3. The theoretical total dose of natural radiation (TD) versus age (T) relationship for a shell from the Uji shell bed. The concentrations of ${ }^{238} \mathrm{U},{ }^{232} \mathrm{Th}$ and $\mathrm{K}_{2} \mathrm{O}$ and the external dose $\left(D_{\text {ex }}\right)$ of $1.12 \mathrm{mG} y / y$ were used following equations for the alpha ray efficiency $(k)$ of 0.2 . The age for disequilibrium $\left(T_{d}\right)$ is obtained graphically from TD by ESR. 
Table 1. Comparison of ESR ages and the age of sediments in two shell beds. The age considering uranium series disequilibrium $\left(T_{d}\right)$ is given with the age for secular equilibrium $\left(T_{e}\right)$

\begin{tabular}{|c|c|c|c|c|c|c|c|c|c|}
\hline \multirow{2}{*}{ Species } & \multicolumn{2}{|c|}{ Radioactivity (ppm)* } & \multirow{2}{*}{$\begin{array}{l}\text { TD } \\
\text { (Gy) }\end{array}$} & \multirow{2}{*}{$\begin{array}{c}\mathrm{D}_{\mathrm{ex}}{ }^{* *} \\
(\mathrm{mG} / \mathrm{y})\end{array}$} & \multirow{2}{*}{$\begin{array}{c}\mathrm{TD}_{\text {in }} * * * \\
(\mathrm{~Gy})\end{array}$} & \multirow{2}{*}{$\begin{array}{c}\mathrm{TD}_{\mathrm{ex}} * * * \\
(\mathrm{~Gy})\end{array}$} & \multicolumn{3}{|c|}{ ESR age (ky) } \\
\hline & & & & & & & $\mathrm{T}_{\mathrm{e}}$ & $\mathrm{T}_{\mathrm{d}}$ & Th/U age**** \\
\hline Hiradoko & & & & & & & & & $115 \pm 10$ \\
\hline Paphia euglypta & & & 170 & & 44 & 126 & 98 & 112 & \\
\hline Arca boncardii & $0.85 \pm 0.017$ & 0.123 & 175 & $1.12 \pm 0.08$ & 45 & 130 & 100 & 115 & $119 \pm 9$ \\
\hline & & & & & & & & & $125 \pm 9$ \\
\hline Novathaca euglypta & & & 110 & & 12 & 98 & 64 & 87 & \\
\hline Callista chinensis & & & 120 & & 13 & 107 & 70 & 95 & \\
\hline Ezocallista brebisiphonata & & & 150 & $(1.12 \pm 0.08)$ & 18 & 132 & 87 & 118 & $120 \pm 9$ \\
\hline Glycymeris yessoeusis & $0.426 \pm 0.01$ & $<0.02$ & 170 & & 20 & 150 & 98 & 133 & \\
\hline
\end{tabular}

* A typical concentration of radioactive elements are used for the age determination.

** The external gamma ray dose rate measured by $\mathrm{TLD}\left(\mathrm{CaSO}_{4}\right)$.

*** The internal total dose, $T D_{\text {in }}=k T D_{\alpha}+T D_{\beta}$, calculated from Equation (6). External total dose is $T D_{e x}=D_{e x} T$. The alpha ray efficiency of $k=0.2$ and $p_{o}={ }^{234} U /{ }^{238} U=1.15$ are used .

**** The age of the shell bed obtained by A. OMURA (1980) from solitary corals by ${ }^{230} \mathrm{Th} /{ }^{234} U$ dating.

\section{Discussion}

Tentative ESR ages of shells from Hiradoko and Uji shell beds have been obtained using a theoretical equation of TD, ${ }^{238} \mathrm{U}$ content and the external radiation dose from the experimental TD determined by ESR. External gamma ray radiation strongly depends on the local environment. The measurements with TLD should be made ideally at each site where the shell is embedded. As this could not be made for shells from Uji shell beds present ages are only tentative ones before a more systematic precise radiation assessment is made. The unexpected variation of the ESR ages for samples from Uji shell beds may be due to the variation of uranium contents in each sample and to that of the external radiation dose at each site. A rough agreement of $\mathrm{T}_{\mathrm{d}}$ with the ${ }^{230} \mathrm{Th} /{ }^{234} \mathrm{U}$ ages is still obtained. The marked contrast to the same relation for corals (IKEYA and OHMURA, 1983) in an infinite medium model is that the obtained age $T_{d}$ is very close to $T_{e}$. This is because the contribution of the internal dose $\left(\mathrm{TD}_{\mathrm{in}}\right)$ to the total dose (TD) is only about 10 percent owing to the small ${ }^{238} \mathrm{U}$ content as is seen in Table 2 and in Fig. 3.

Several other problems involved in the radiation assessment are now discussed for future refinement of ESR ages.

Uranium accumulation Modern shells have extremely low ${ }^{238} \mathrm{U}$ content in contrast to fossil shells. This is presumably because of uranium accumulation in fossils, which increases the internal dose rate. However, the radiation dose is mainly due to gamma-rays out of the environment. Hence, the process of uranium accumulation affects the ESR age only slightly for fossil shells; a model of a linear uranium accumulation treated in the previous work for fossil bones (IKEYA 1982) gave nearly the same age as the present one.

Leaching of radioactive elements There are arguments that the ${ }^{234} \mathrm{U} /{ }^{238} \mathrm{U}$ ratio, $p_{o}$ in shells is much larger than about 1.15 in sea water or in corals (KoNISHI et al., 1974). It was demonstrated that the recoil atom by alpha disintegration in dissolved in water easily and that it is the cause of ${ }^{234} \mathrm{U} /{ }^{238} \mathrm{U}$ discrepancy of ground water (KIGOSHI 1971). Hence, the ${ }^{230} \mathrm{Th} /{ }^{234} \mathrm{U}$ dating of open system shells is not more trustworthy than that of closed system corals. This was the reason why OMURA (1980) used corals for the age determination of Hiradoko and Uji shell beds. The alpha recoil leaching problem might be also involved for the radiation assess- 
ment in ESR dating of shells. However, it should be noted that the integrated total dose (TD) including the one out of the environment is the major concern in ESR dating. Therefore, disequilibrium due to the slight leaching of some specific elements may affect the internal total dose $\left(T_{D_{\text {in }}}\right)$ to some extent but not so much the TD. It would be only about $20-30$ percent of $\mathrm{TD}_{\text {in }}$ which constitutes $10-20$ percent of TD. It is mainly the external dose that gives the TD for shells.

External beta ray dose The effect of beta rays out of the environment has been neglected in the present study. The beta ray dose for an infinite medium of the sediments at Hiradoko was estimated to be around $2 \mathrm{mGy} / \mathrm{y}$ from the concentrations of ${ }^{238} \mathrm{U},{ }^{232} \mathrm{Th}$ and $\mathrm{K}$. On the other hand, gamma rays dose rate was $1.2 \mathrm{mGy} /$ $y$ assuming radiation equilibrium (BELL 1979) in good concordance with the results $(1.12 \mathrm{mGy} / \mathrm{y})$ of TLD measurements. The contribution of beta rays must be evaluated as suggested by YoK̇oyama and NGUYen (1980) on the basis of the surface range of the material for precise measurements. However, if the surface portion is removed by chemical etching with acids or mechanically, the effect would be negligibly small to the total dose of natural radiation.

Variation of external dose Major problem is the possible variation of the external gamma ray dose rate $\left(D_{e x}\right)$ in the shell bed over the embedded time. Migration of uranium and other radioactive elements in sediments would result in considerable errors in the age determination, since the external gamma ray dose rate is the main factor determining the age as was suggested in the previous work (IKEYA and OHMURA, 1981).

\section{Initial ${ }^{226} \mathrm{Ra}$ incorporation Divalent ${ }^{226} \mathrm{Ra}$} ions enter the carbonate lattice of shells. For corals the activity ratio ${ }^{226} \mathrm{Ra} /{ }^{238} \mathrm{U}$ is about $2-3$ percent (KOMURA, 1982) and shifts the age by only 100y at most (IKeYA and OHMURA, 1983). Precise radiometric measurements have not been made so far. The age of present shells, however, suggests that the effect of ${ }^{226} \mathrm{Ra}$ with the half life of 1860 years would be negligibly small on Pleistocene shells.

Recrystallization An age of carbonate in ESR dating is in this case the age of crystallization. If the alpha damaged region were dissolved and recrystallized or if a part of the microcrystal in the shell were recrystallized, we would get a much younger age than the real age of the shell. Hence, sufficient precaution should be taken to avoid altered shells, especially those exposed to fresh ground water. Coral dating by ESR at different marine terraces in the Ryukyu Islands without such precaution has given young ages owing to the problem of recrystallization.

These are the problems and limitation of ESR method as an absolute dating technique for shells. However, most of them can be solved or avoided if a precise assessment of the internal and external radiation is made for well selected samples. Although some problems are still left and the refinement of the ages are needed in this work of shell dating, the first use of TD for a finite medium model on the basis of ${ }^{238} \mathrm{U}$-series disequilibrium has given reasonable absolute ESR ages consistent with ${ }^{230} \mathrm{Th} /{ }^{234} \mathrm{U}$-method. It is hoped that the procedures used in this work for a finite size sample are applied to dating small fossils in sediments. Systematic studies of shells in marine terraces will solve problems in geology and geography.

It is concluded that ESR dating covering the time range from about a thousand to nearly a million years can thus be an absolute dating technique even for partially open system shells in Quaternary Era, if a proper assessment of the environmental radiation is made.

Acknowledgment-The authors thank Dr. A. OMURA at Kanazawa University for the analysis of radioactivity, discussion on shell dating by $\mathrm{Th} / \mathrm{U}$ method and information on the localities. We also appreciate Mr. Y. TSUI, Ms. F. FUJIMOTO and Ms. R. SUEHIRO for the help in ESR measurements. 


\section{REFERENCES}

AItKen, M. J. (1974) Physics and archaeology, 2nd edition, Clarendon Press, Oxford.

BELL, W. T. (1979) The assessment of the radiation dose for thermoluminescence dating, Archeometry 21, 243.

FUJII, S. (1976) The problem of the Uji Transgression (in Japanese). Bull. Japan Sea Res. Inst. Kanazawa Univ. 8, 27-35.

IKEYA, M. (1975) Dating a stalactite by paramagnetic resonance. Nature 255, 46-48.

IKEYA, M. (1978) Electron spin resonance as a method of dating. Archaeometry 20,147-158.

IKEYA, M. and MIKI, T. (1980) Electron spin resonance dating of animal and human bones. Science 207, 977-979.

IKEYA, M. and OHMURA, K. (1981) Dating of fossil shells with electron spin resonance. J. Geol. 89, 230-247.

IKEYA, M. (1982) A model of a linear uranium accumulation for ESR ages of Heidelberg (Mauer) and Tautavel bones. Japan. J. Appl. Phys. Lett. 21, L690-L692.

IKEYA, M. and OHMURA, K. (1983) Comparison of ESR ages of corals at marine terraces with ${ }^{14} \mathrm{C}$ and $\mathrm{Th}^{230} / \mathrm{U}^{234}$ ages. Earth Planet. Sci. Lett. 56 (in press).

IKEYA, M. (1984) Dating and age determination of biological materials (eds. M. R. ZIMMERMAN and L. ANGEL) Chapt. 3 Electron Spin Resonance, Croom \& Helm, London (in press).

KIGOSHI, K. (1971) Alpha-recoil thorium-234: Dissolution into water and uranium-234/uranium-238 disequilibrium in nature. Science 173,47-48.
KomURA, K. (1982) Dating by non-destructive gamma-ray spectroscopy (in Japanese). Archaeology and Natural Sciences 14, 1-24.

KoNISHI, K., OMURA, A. and NAKAMICHI, O. (1974) Radiometric coral ages and sea level records from the late Quaternary reef complexes of the Ryukyu Islands. Proc. 2nd Intern. Coral Reef Symp. 595613.

MIKI, T. and IKEYA, M. (1978) Thermoluminescence and ESR of Akiyoshi stalactite. Japan. J. Appl. Phys. 17, 1703-1704.

OMURA, A. (1976) Thorium and protactinium isotopes in some present-day hermatypic corals and their implications to dating. Trans. Proc. Palaeont. Soc. Japan. N. S. 101, 271-290.

OMURA, A. (1980) Uranium-series age of the Hirradoko and Uji shell beds, Noto Peninsula, Central Japan. Trans. Proc. Palaeont. Sco. Japan N. S. 117, 247-253.

UJIIE, H. (1975) Geological history of the Japan Sea revealed by sediments (in Japanese). Natural Science and Museum 42, 55-66.

WINTLE, A. G. (1978) A thermoluminescence dating study of some Quaternary calcite. Canad. J. Earth Sci. 15, 1977.

Yokoyama, Y. and NGUYen, H. V. (1980) Direct and non-destructive dating of marine sediments, manganese nodules, and corals by high resolution gamma-ray spectrometry. In: Isotope marine chemistry (ed. E. D. GoldberG, Y. HORIBE and K. SARUHASHI) Chapt. 14, Uchida Roukakubo, Tokyo. ZELlER, E. J., LEVY, P. W. and MATTERN, P. L. (1967) Geological dating by electron spin resonance. Proc. Symposium Radioactive Dating \& Low Level Counting, IAEÀ 531-540. 